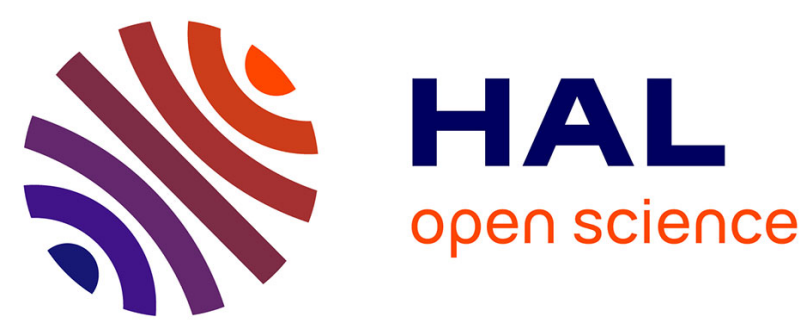

\title{
Water/ice phase transition: The role of zirconium acetate, a compound with ice-shaping properties
}

Moreno Marcellini, Francisco M. Fernandes, Dmytro Dedovets, Sylvain Deville

\section{To cite this version:}

Moreno Marcellini, Francisco M. Fernandes, Dmytro Dedovets, Sylvain Deville. Water/ice phase transition: The role of zirconium acetate, a compound with ice-shaping properties. Journal of Chemical Physics, 2017, 146 (14), pp.144504. 10.1063/1.4979845 . hal-01520211

\section{HAL Id: hal-01520211 https://hal.sorbonne-universite.fr/hal-01520211}

Submitted on 10 May 2017

HAL is a multi-disciplinary open access archive for the deposit and dissemination of scientific research documents, whether they are published or not. The documents may come from teaching and research institutions in France or abroad, or from public or private research centers.
L'archive ouverte pluridisciplinaire HAL, est destinée au dépôt et à la diffusion de documents scientifiques de niveau recherche, publiés ou non, émanant des établissements d'enseignement et de recherche français ou étrangers, des laboratoires publics ou privés. 


\section{Water/ice phase transition: The role of zirconium acetate, a compound with ice- shaping properties}

Moreno Marcellini, Francisco M. Fernandes, Dmytro Dedovets, and Sylvain Deville

Citation: The Journal of Chemical Physics 146, 144504 (2017); doi: 10.1063/1.4979845

View online: http://dx.doi.org/10.1063/1.4979845

View Table of Contents: http://aip.scitation.org/toc/jcp/146/14

Published by the American Institute of Physics

\section{Articles you may be interested in}

Perspective: Echoes in 2D-Raman-THz spectroscopy

The Journal of Chemical Physics 146, 130901130901 (2017); 10.1063/1.4979288

Temperature of maximum density and excess properties of short-chain alcohol aqueous solutions: A simplified model simulation study

The Journal of Chemical Physics 146, 144503144503 (2017); 10.1063/1.4979806

Perspective: Found in translation: Quantum chemical tools for grasping non-covalent interactions The Journal of Chemical Physics 146, 120901120901 (2017); 10.1063/1.4978951

Thermodynamic integration methods, infinite swapping, and the calculation of generalized averages The Journal of Chemical Physics 146, 134111134111 (2017); 10.1063/1.4979493

A Gaussian theory for fluctuations in simple liquids

The Journal of Chemical Physics 146, 134507134507 (2017); 10.1063/1.4979659

Anomalous sound attenuation in Voronoi liquid

The Journal of Chemical Physics 146, 144502144502 (2017); 10.1063/1.4979720

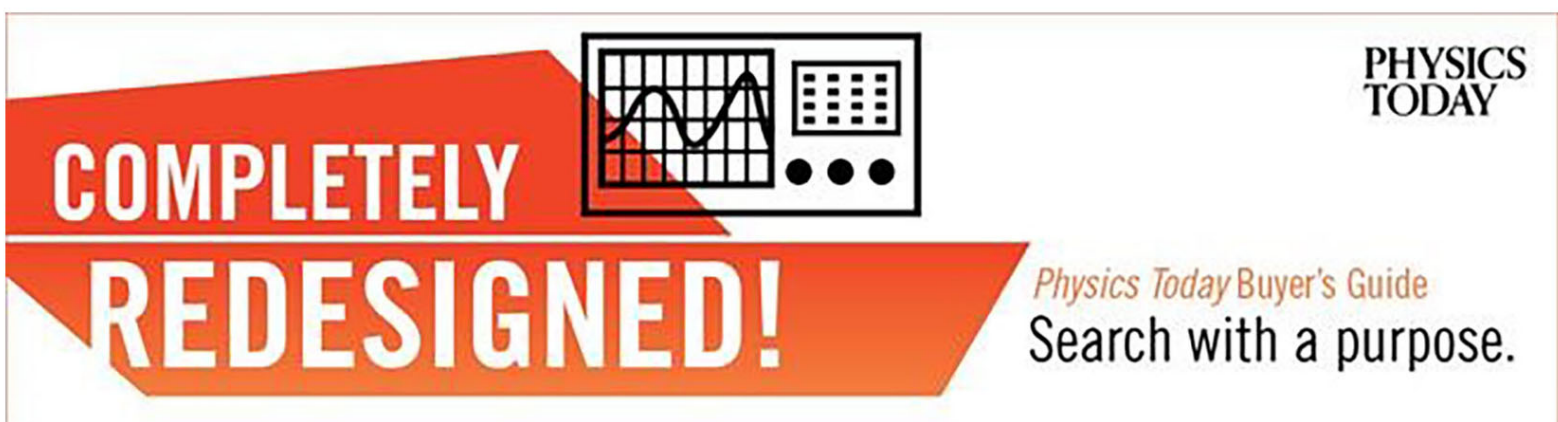




\title{
Water/ice phase transition: The role of zirconium acetate, a compound with ice-shaping properties
}

\author{
Moreno Marcellini, ${ }^{1}$ Francisco M. Fernandes, ${ }^{2}$ Dmytro Dedovets, ${ }^{1}$ and Sylvain Deville ${ }^{1, a)}$ \\ ${ }^{1}$ Ceramic Synthesis and Functionalization Lab, UMR3080 CNRS/Saint-Gobain, 84306 Cavaillon, France \\ ${ }^{2}$ Laboratoire de Chimie de la Matière Condensée de Paris, Université Pierre et Marie Curie, \\ Sorbonne Universités, UMR7574, 4 Place Jussieu, 75005 Paris, France
}

(Received 18 November 2016; accepted 15 March 2017; published online 13 April 2017)

\begin{abstract}
Few compounds feature ice-shaping properties. Zirconium acetate is one of the very few inorganic compounds reported so far to have ice-shaping properties similar to that of ice-shaping proteins, encountered in many organisms living at low temperature. When a zirconium acetate solution is frozen, oriented and perfectly hexagonal ice crystals can be formed and their growth follows the temperature gradient. To shed light on the water/ice phase transition while freezing zirconium acetate solution, we carried out differential scanning calorimetry measurements. From our results, we estimate how many water molecules do not freeze because of their interaction with $\mathrm{Zr}$ cations. We estimate the colligative properties of the $\mathrm{Zr}$ acetate on the apparent critical temperature. We further show that the phase transition is unaffected by the nature of the base which is used to adjust the $\mathrm{pH}$. Our results provide thus new hints on the ice-shaping mechanism of zirconium acetate. Published by AIP Publishing. [http://dx.doi.org/10.1063/1.4979845]
\end{abstract}

\section{INTRODUCTION}

Water molecules, albeit composed by 3 atoms only, show complex behaviors and anomalies. Several theoretical models were proposed to describe its physico-chemical properties: ${ }^{1}$ each model can suitably describe only certain characteristics. For example, the nucleation of ice in water is difficult to predict. Indeed, the water/ice phase transition is a very common but still puzzling and challenging phenomenon.

The nucleation of ice crystals occurs both in vapor and in liquid phases. Although it is difficult to maintain large volumes of water below $0{ }^{\circ} \mathrm{C}$ without nucleation, a small volume can be held in supercooled conditions. ${ }^{2}$ Pradzynski et al. ${ }^{3}$ found that at least $275 \pm 25$ water molecules are required to initiate the ice nucleation. The freezing of water in distinct physicochemical conditions results in different ice patterns, such as those of snow crystals, or the dendritic and cellular structure grown in supercooled water. ${ }^{2,4}$

The nucleation of water is hindered by solutes: $\mathrm{NaCl}$ in sea water, for instance, lowers the freezing point by $\approx-1.8^{\circ} \mathrm{C}$. Colloidal particles can also depress the freezing point of water. ${ }^{5}$ Ice is pure water. At the liquid-solid phase transition, water expels most of the ions and particles, which form brine channels between the ice crystals ${ }^{6}$ while releasing a latent heat $\Delta H_{f}=333.6 \mathrm{~kJ} / \mathrm{kg} .{ }^{2}$ Nevertheless, some ions are easily incorporated in ice.

Zirconium acetate $(\mathrm{ZrAc})$, a moderately water soluble crystalline $\mathrm{Zr}$ source, decomposes to zirconium oxide on calcination at high temperature. ${ }^{7}$ The physico-chemical processes leading to densification of liquid precursor solutions of $\mathrm{ZrAc}$ have been characterized by several methods. ${ }^{8-11}$ The behavior of $\mathrm{ZrAc}$ solutions at temperature below the water/ice

\footnotetext{
a) sylvain.deville@ saint-gobain.com
}

phase-transition was not investigated until $\mathrm{ZrAc}$ was used in ice-templating (also called freeze casting). ${ }^{12}$ Ice templating is a material processing route based on the directional growth of ice crystals in colloidal suspensions and the successive removal of water by sublimation. The porosity is thus templated by the ice crystals. The templated microstructures, architectures, and properties are related to the morphology of ice crystals grown during freezing. In this process, $\mathrm{ZrAc}$ can be used either as an additive or as a ceramic precursor.

The use of $\mathrm{ZrAc}$ as an additive revealed its surprising ice-shaping properties. ${ }^{13}$ When a $\mathrm{ZrAc}$ solution is frozen in a narrow interval of $\mathrm{pH}$ (3.6-4.3) and concentration $(\approx 9$ to $22.6 \mathrm{~g} / \mathrm{l}$ of $\mathrm{Zr}$ ), faceted hexagonal ice crystals nucleate and grow along the direction of freezing (Fig. 1). Such faceting is similar to the effects of ice-shaping proteins (ISPs) that in fishes, ${ }^{14}$ insects, ${ }^{15}$ and plants ${ }^{16}$ hinder, for example, the growth of large ice crystals and stabilize ice crystals in specific shapes. $\mathrm{ZrAc}$ (and the less powerful $\mathrm{Zr}$ hydroacetate) ${ }^{13,17}$ is so far one of the very few inorganic compounds that functions like ISPs. However, ISPs work at concentration of $\mu \mathrm{mol}$ or lower (which corresponds, on average, to 0.1 to $1 \mathrm{~g} / \mathrm{L}$ ), whereas for $\mathrm{ZrAc}$, the lowest reported concentration for effective ice shaping properties is $\approx 0.10 \mathrm{~mol}(9 \mathrm{~g} / \mathrm{l} \mathrm{of} \mathrm{Zr}){ }^{13}$ The interactions of ISPs with ice are therefore probably much stronger than that of ZrAc.

To further understand the process that controls the growth of ice crystals in $\mathrm{ZrAc}$ solutions, we froze several $\mathrm{ZrAc}$ solutions, prepared in two different ways, and measured by Differential Scanning Calorimetry (DSC) the liquid/solid phase transition. From our results, we assessed the amount of ice in the sample and estimated the radius of interaction of $\mathrm{Zr}$ cations. We further show that the phase transition is a colligative effect of the $\mathrm{Zr}$ concentration, independently of the base used for $\mathrm{pH}$ correction. 


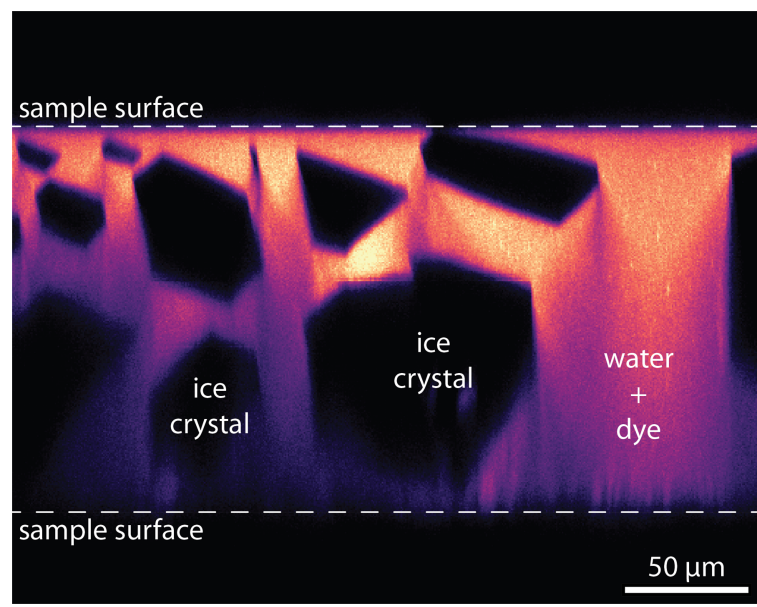

FIG. 1. Cryoconfocal image of the cross section of ice crystals growing at $1 \mu \mathrm{m} / \mathrm{s}$ in the presence of zirconium acetate ( $\mathrm{Zr}$ concentration: $18 \mathrm{~g} / \mathrm{l})$. The dye (sulforhodamine B) is expelled from the growing crystals, and the crystals appear thus as dark. ${ }^{18}$ The ice crystals are sharp and faceted. The cross section was obtained perpendicular to the direction of the temperature gradient along which the ice crystals grow.

\section{SAMPLE PREPARATION}

A solution of $\mathrm{ZrAc}$ (in-house preparation of SaintGobain ${ }^{19}$ ), with initial $\mathrm{Zr}$ concentration of $22.6 \mathrm{~g} / \mathrm{l}$ (solution $\# 1$ ) and original $\mathrm{pH}=2.6$, was diluted in deionized water to obtain two other solutions with equivalent starting $\mathrm{Zr}$ concentrations of $13.3 \mathrm{~g} / \mathrm{l}(\mathrm{pH}=3.2$, solution \#3) and $18 \mathrm{~g} / \mathrm{l}$ ( $\mathrm{pH}=3.1$, solution \#2): each was prepared in two batches. The $\mathrm{pH}$ of one of the batches was then adjusted to $\mathrm{pH}=4.0 \pm 0.1$ by adding $\mathrm{NaOH}$ powder and $\mathrm{HCl}$ solution at $37 \mathrm{wt}$. \% (Sigma Aldrich): solutions $\# X(\mathrm{NaOH})$. This $\mathrm{pH}$ value is the optimal one to cause hexagonal ice-faceting while freezing the solution. ${ }^{13,17,20}$ The $\mathrm{pH}$ of the latter batch was carefully set, without overshooting, to $\mathrm{pH} \approx 4$ with $\mathrm{TMAOH}$ solution (tetramethylammonium hydroxide, Sigma Aldrich, concentration of 10 wt. $\%$ in water): solutions $\# X(\mathrm{TMAOH})$. TMAOH is a strong chaotrope molecule believed to weaken the hydrogen bonds network of water. It can entrap several molecules of water by hydrogen bonds ${ }^{21,22}$ producing clathrates. ${ }^{23}$ Both $\mathrm{Na}^{+}$and $\mathrm{Cl}^{-}$are in the middle of the Hofmeister series. ${ }^{24-26}$ The acetate group is more kosmotrope than $\mathrm{Cl}^{-} .{ }^{27}$ By probing two different sets of solutions, we can also assess whether the chaotrope/kosmotrope natures of the two bases affect the liquid/solid phase transition. The low initial concentration of the TMA-OH solution and its high $\mathrm{pK}_{b}=4.2$ caused large shifts in the final $\mathrm{Zr}$ concentration after the $\mathrm{pH}$ adjustment. The final concentration of the solutions adjusted with $\mathrm{NaOH} / \mathrm{HCl}$ remained unchanged, see Table I. For each solution, we also prepared the corresponding reference solutions made up by a volume of water equivalent to the initial volume of the three solutions and the same amount of bases needed to adjust the pHs.

DSC measurements were carried out in $\mathrm{N}_{2}$ atmosphere. The cooling/heating rate was set to $5^{\circ} \mathrm{C} / \mathrm{min}$ in the close cycle from +40 to $-80^{\circ} \mathrm{C}$ : for the \#1(TMAOH) and \#3(TMAOH) samples, we recorded additional thermograms at $1{ }^{\circ} \mathrm{C} / \mathrm{min}$. We recorded two cycles per solution. The chosen freezing rate corresponds to ice shaping conditions used in freeze casting.
TABLE I. Samples and estimated Zr concentration.

\begin{tabular}{lccc}
\hline \hline Sample & $\mathrm{NaOH} / \mathrm{HCl}(\mathrm{g} / \mathrm{l})$ & $\mathrm{TMA}-\mathrm{OH}(\mathrm{g} / \mathrm{l})$ & Before $\mathrm{pH}$ adj. \\
\hline$\# 1$ & $\approx 22.6$ & $\approx 16.7$ & 22.6 \\
$\# 2$ & $\approx 17.7$ & $\approx 14.5$ & 18 \\
$\# 3$ & $\approx 13.1$ & $\approx 11.2$ & 13.3 \\
\hline \hline
\end{tabular}

The data analysis was performed with the Universal Analysis 2000 (TA Instruments) software.

\section{RESULTS AND DISCUSSION}

The thermograms for the $\# X(\mathrm{NaOH})$ solutions are shown in Fig. 2. During the cooling semi-cycle, the freezing (critical) point is apparently depressed to temperatures $\leq-20^{\circ} \mathrm{C}$ because the phase transition occurs in supercooled state, triggering an avalanche-alike dendritic formation of ice crystals. ${ }^{4}$ The temperature increases during the phase transition for $\# 3(\mathrm{NaOH})$. This artifact is due to the instrument not able to fully withdraw the latent heat. Likewise, the double peak for the $\# 2(\mathrm{NaOH})$ is due to the spontaneous ice nucleation in supercooled conditions. Similar experiments on the $\# X$ (TMAOH) solutions give the results shown in Fig. 3. To understand whether the temperature scan rate causes a change in the melting temperature and the released heat, in Figure 4 we compared the thermogram of the \#3(TMAOH) sample taken at the rates 5 and $1{ }^{\circ} \mathrm{C} / \mathrm{min}$. We note that the temperature difference at the melting valley is significantly small despite the large difference in heat flow. Saeed et al. ${ }^{28}$ have recently discussed how the difference in results can arise from using various temperature scan rates and amount of sample material. The thermal hysteresis observed can be related to different phenomena: the nucleation of ice is facilitated by nucleation points, such as, for example, dispersed particles, gas bubbles. If those lack, it is possible to bring water solutions in supercooled temperature. As soon as ice nucleates, it quickly releases the excess energy and ice crystals grow. If solutes are solved, then ice traps brines between the crystals. ${ }^{18}$ Melting, instead, looks alike a fully thermodynamic process. It is also possible that the small thermal hysteresis previously reported for $\mathrm{ZrAc}^{17}$

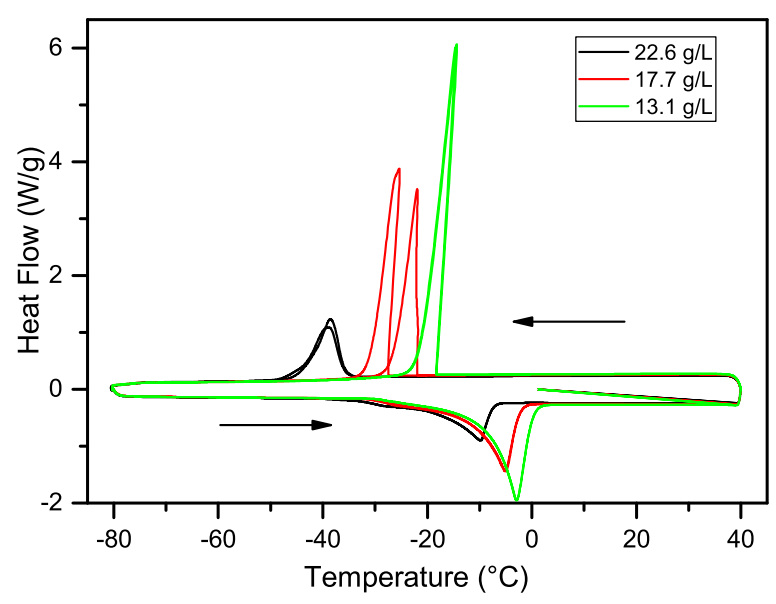

FIG. 2. Full thermograms of $\# X(\mathrm{NaOH})$ solutions. Arrows indicate the direction of the cycle. 


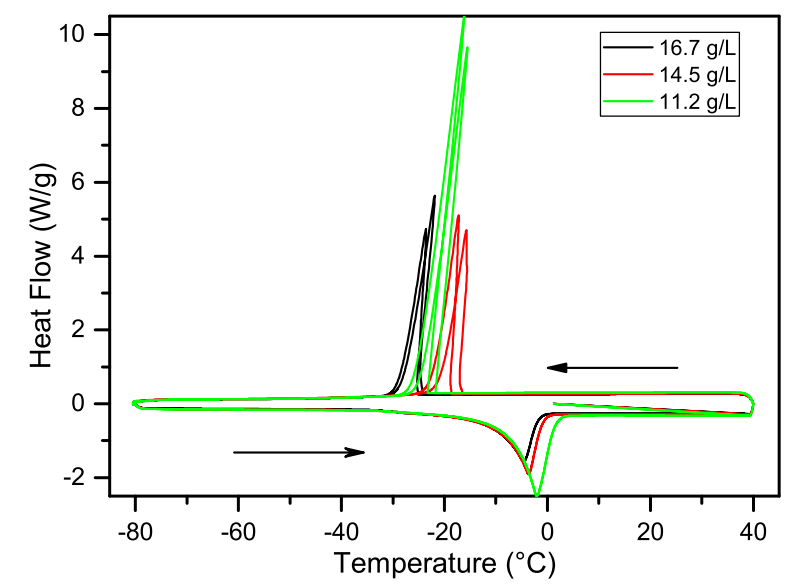

FIG. 3. Like in Fig. 2, thermograms for the $\# X(T M A O H)$ solutions. Similarly to the $\# X(\mathrm{NaOH})$ case, the apparent freezing temperatures correlate with the $\mathrm{Zr}$ concentration.

contributes in addition to the thermal hysteresis during freeze/thaw cycles reported here.

Hereby we define the apparent critical temperature $T_{c}$ as the onset temperature of the solid/liquid phase transition. The onset temperatures are defined as the intersection, prior to the peak temperature, of the tangent of the peak with the extrapolated baseline and they should stay unchanged when the peak temperature shifts due to the change in heating rate or sample preparation. It usually is a more robust indicator of the thermal process by representing the starting point of the phase transition. Lower heating rate provides a more accurate measurement of the melting temperature, and larger heating rate allows us to measure the enthalpy of fusion with better accuracy. In our measurements, the larger is the heating rate the wider seems, in the temperature/heat-flow space, the phase transition. In Table II, we report the calculated results for $T_{c}, T_{\min }\left(T_{\min }\right.$ are the measured temperatures at the valley minima), and $\Delta H$ for two different temperature scan rates for \#1(TMAOH) and \#3(TMAOH) solutions. The temperature values of $T_{c}$ for a consistent set of measurements and samples are reported in Table III and plotted in Fig. 5 with the corresponding results of reference solutions. These results tell us

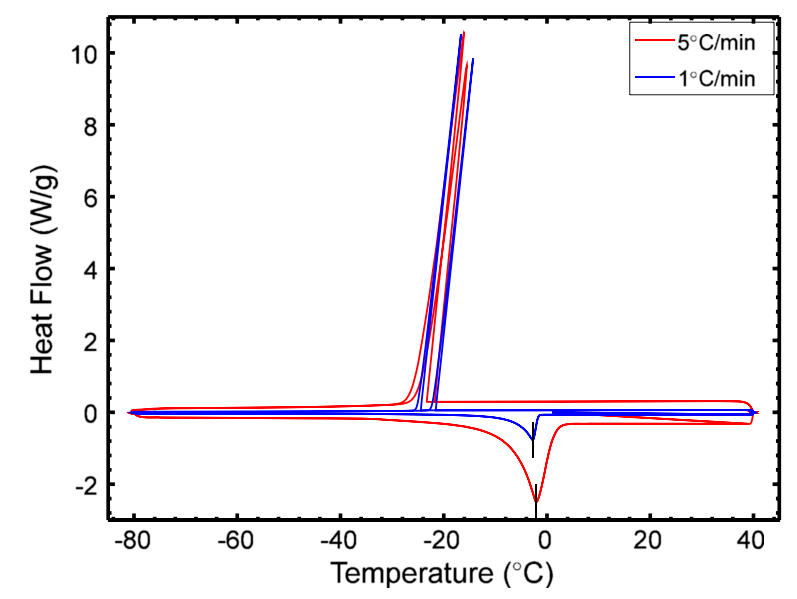

FIG. 4. Thermogram for the \#3(TMAOH) solution at two temperature scan rates. Apparently, there is no significant difference between the two phase transitions. The vertical black bars are set at the valley minima.
TABLE II. Computed $T_{c}, T_{\min }$, and $\Delta H$ for two solutions measured at two different temperature scan rates.

\begin{tabular}{lcccccc}
\hline \hline $\begin{array}{l}\mathrm{dT} / \mathrm{dt} \\
\left({ }^{\circ} \mathrm{C} / \mathrm{min}\right)\end{array}$ & $\begin{array}{c}\text { TMAOH } \\
\text { sample }\end{array}$ & $\begin{array}{c}\text { Cycle } \\
(\mathrm{g} / \mathrm{l})\end{array}$ & $\begin{array}{c}\mathrm{Zr} \\
(\mathrm{g} / \mathrm{l})\end{array}$ & $\begin{array}{c}T_{c} \\
\left({ }^{\circ} \mathrm{C}\right)\end{array}$ & $\begin{array}{c}T_{\min } \\
\left({ }^{\circ} \mathrm{C}\right)\end{array}$ & $\begin{array}{c}\Delta H \\
(\mathrm{~J} / \mathrm{g})\end{array}$ \\
\hline 1 & $\# 1$ & 1 & 16.7 & -9.79 & -5.08 & 106.0 \\
1 & & 2 & 16.7 & -9.84 & -5.08 & 105.9 \\
5 & & 1 & 16.7 & -10.24 & -4.60 & 107.7 \\
5 & & 2 & 16.7 & -10.25 & -4.60 & 106.3 \\
\hline 1 & \multirow{2}{*}{$\# 3$} & 1 & 11.2 & -6.11 & -2.76 & 171.5 \\
1 & & 2 & 11.2 & -6.02 & -2.74 & 169.7 \\
5 & & 1 & 11.2 & -6.81 & -2.06 & 168.7 \\
5 & & 2 & 11.2 & -6.85 & -2.10 & 168.4 \\
\hline \hline
\end{tabular}

that the apparent $T_{c}$ is a colligative property of $\mathrm{ZrAc}$ concentration. For example, \#2(NaOH) and \#3(NaOH) share close concentrations with \#1(TMAOH) and \#2(TMAOH), respectively, and their $T_{c}$ are quite similar. When the $\mathrm{pHs}$ of the original solutions are adjusted with $\mathrm{NaOH} / \mathrm{HCl}$, the large difference between the $T_{c}$ of the samples and reference solutions hints to how strong the interaction between the solute ( $\mathrm{ZrAc})$ and the surrounding water shell is.

Various experimental results reported in past literature commonly agree that $\mathrm{ZrAc}$ and other $\mathrm{Zr}$ of monoprotic acid, in aqueous solution hydrolyze forming cyclic tetramers. The $\mathrm{Zr}$ ions are connected by hydroxo-bridges. ${ }^{29-31}$ The stability of the cyclic tetramer has been also proven by computation. ${ }^{32}$ The polymerization reaction of tetramers into edge-sharing chains of tetramers ${ }^{33}$ occurs depending on the concentration, the $\mathrm{pH}$, and experimental conditions.

We thus hypothesize that the cyclic $\mathrm{Zr}$ tetramers organize, in water, as edge-sharing chains of tetramers, which were found both at room conditions ${ }^{33}$ and at a pressure of $23 \mathrm{MPa} .{ }^{34}$ The cyclic $\mathrm{Zr}$ tetramer is the universal structural motif: similar double chained $\mathrm{Zr}$ tetramer polymer has also been found at room temperature and pressure of $25 \mathrm{MPa}$ in precursor for yttria-stabilized zirconia nanoparticles solved in methanol ${ }^{11}$ and it also occurs in equilibrium with hexanuclear $\mathrm{Zr}$ acetate species. ${ }^{31}$ Dippel et al. ${ }^{11}$ report a persistence order of the double chain of $10 \AA$, before a twist of the chain occurs, in pressure condition of $23 \mathrm{MPa}$.

Such chain structures decorated by acetate groups should resemble the one of ISPs from, for example, spruce budworm ${ }^{35}$ or from winter flounder. ${ }^{36}$ Similar idea has been recently proposed for a newly discovered organic compound that displays ice-shaping features. ${ }^{37}$ These large structures (edge-sharing chains of tetramers) can interact with several water shells thanks to the ability of acetate groups to alter the hydrogen bonds network in the neighborhood. We hypothesize

TABLE III. Apparent $T_{c}$ of $\mathrm{ZrAc}$ and reference solutions. (The latter in parentheses.)

\begin{tabular}{lcccr}
\hline \hline Sample & $\mathrm{Zr}(\mathrm{g} / \mathrm{l})$ & $\mathrm{NaOH} / \mathrm{HCl}\left({ }^{\circ} \mathrm{C}\right)$ & $\mathrm{Zr}(\mathrm{g} / \mathrm{l})$ & $\mathrm{TMAOH}\left({ }^{\circ} \mathrm{C}\right)$ \\
\hline$\# 1$ & 22.6 & $-18.61(-3.37)$ & 16.7 & $-10.50(-9.34)$ \\
$\# 2$ & 17.7 & $-11.45(-3.58)$ & 14.5 & $-8.91(-5.62)$ \\
$\# 3$ & 13.1 & $-8.15(-2.86)$ & 11.2 & $-6.97(-4.80)$ \\
\hline \hline
\end{tabular}




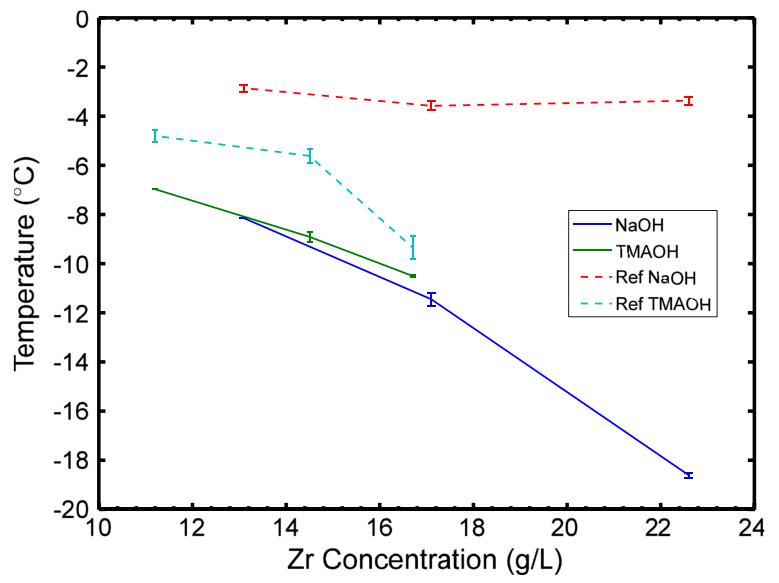

FIG. 5. $T_{c}$ of the solutions. $T_{c}$ is a colligative property of $\mathrm{Zr}$ concentration. (The lines are guide for the eyes.)

that likewise ISPs, these structures should adsorb onto the blooming ice crystals and cause their directional and faceted growth. Further microscopic measurements are needed to solve the topology of the organization of $\mathrm{Zr}$ ions under the conditions investigated here.

The latent heat $L$ released at the phase transition depends only on the amount of water that participates in the phase transition. The ratio between the experimental and the tabulated $\Delta H_{f}$ value represents the amount of water that has taken part to the phase transition. Even though the enthalpy of fusion of water $\Delta H_{f}$ depends on the temperature ${ }^{38}$ and within our temperature range, the change on $\Delta H_{f}$ is below $1 \% ; \Delta H_{f}$ decreases while increasing the pressure: from tabulated data, ${ }^{39}$ we can estimate that the decrement is about $0.1 \%$ per $0.1 \mathrm{MPa}$; for a correct measurement of $\Delta H_{f}$ of the various solutions, we should properly proceed: ${ }^{40}$ this is well beyond the scope of this work. In this way, we estimate that the systematic errors in our calculation of frozen water should not exceed $3 \%$. These results, computed on the heating semi-cycle, are in Table IV and plotted in Fig. 6. Clearly the physico-chemical properties of the bases do not interfere with the phase transition. For example, the samples \#2(NAOH) and \#1(TMAOH) contain similar amount of $\mathrm{ZrAc}(17.7 \mathrm{~g} / \mathrm{l}$ versus $16.7 \mathrm{~g} / \mathrm{l})$ and the ice content is similar. Thus, we may conclude that the thermodynamics of the process is due exclusively to $\mathrm{ZrAc}$, strengthening the hypothesis that the ice-shaping properties of $\mathrm{ZrAc}$ are colligative. If we approximate the solutions as composed of water and $\mathrm{ZrAc}$, we can estimate, from the amount of ice, how many molecules of water do not participate in the phase transition due to their interaction with the $\mathrm{Zr}$ cations. This approach is eased in the case of $\# X(\mathrm{NaOH})$ solutions, where the $\mathrm{NaOH} / \mathrm{HCl}$ content is minimal. Thus, for the solution $\# 1(\mathrm{NaOH})$, we estimate that 180 water molecules per

TABLE IV. Amount (percent) of frozen water in each sample. In parentheses the values for the reference solutions.

\begin{tabular}{lcccc}
\hline \hline Sample & $\mathrm{Zr}(\mathrm{g} / \mathrm{l})$ & $\mathrm{NaOH} / \mathrm{HCl}(\%)$ & $\mathrm{Zr}(\mathrm{g} / \mathrm{l})$ & $\mathrm{TMA}-\mathrm{OH}(\%)$ \\
\hline$\# 1$ & 22.6 & $19(71)$ & 16.7 & $35(53)$ \\
$\# 2$ & 17.7 & $31(74)$ & 14.5 & $39(62)$ \\
$\# 3$ & 13.1 & $40(77)$ & 11.2 & $51(66)$ \\
\hline \hline
\end{tabular}

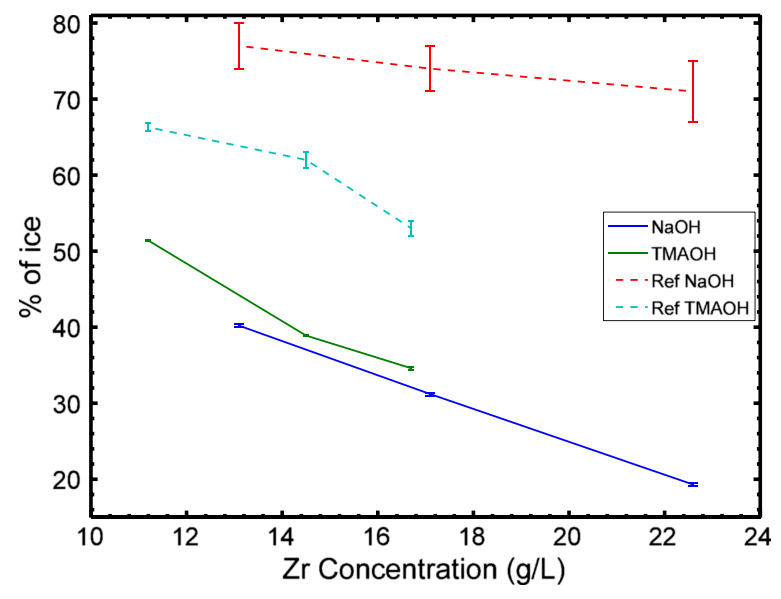

FIG. 6. Ice contents in the solutions. (The lines are guides for the eyes.)

TABLE V. Water molecules per Zr cation; radii of interaction per $\mathrm{Zr}$ cation; $\mathrm{Zr}$ concentration after phase transition in water. As $\mathrm{Zr}$ is expelled from the growing ice, its concentration in the liquid is higher after the phase transition.

\begin{tabular}{lccc}
\hline \hline Sample & $\mathrm{H}_{2} \mathrm{O}$ molecules & Radius $(\mathrm{nm})$ & $\mathrm{Zr}(\mathrm{g} / \mathrm{l})$ \\
\hline$\# 1(\mathrm{NAOH})$ & 180 & 1.74 & 27.9 \\
$\# 2(\mathrm{NAOH})$ & 198 & 1.80 & 25.7 \\
$\# 3(\mathrm{NAOH})$ & 232 & 1.89 & 21.8 \\
\hline \hline
\end{tabular}

Zr cation do not contribute to the phase transition. We can represent it as a sphere of radius $r \approx 1.74 \mathrm{~nm}$ (see Table V). To give an idea of how large the sphere of interaction for $\mathrm{Zr}$ cations is, the $\mathrm{Zr}-\mathrm{Zr}$ interdistance is $\approx 0.32 \mathrm{~nm}$. For example, the TMAOH binds 25 water molecules by hydrogen bond. ${ }^{21,41}$ The percent of frozen water in Table IV represents, to a first approximation, the volume of ice. Since the ice turns into porosity in the final material, this volume is thus an indirect measurement of the overall porosity in ice-templated materials. While measuring the reference solutions, we noted a secondary peak at lower temperature occurring for the solution loaded exclusively with TMA-OH, Fig. 7. We believe that this extra phase transition could result from the formation of TMA-OH clathrates which have already been observed by Mootz and Seidel. ${ }^{23}$

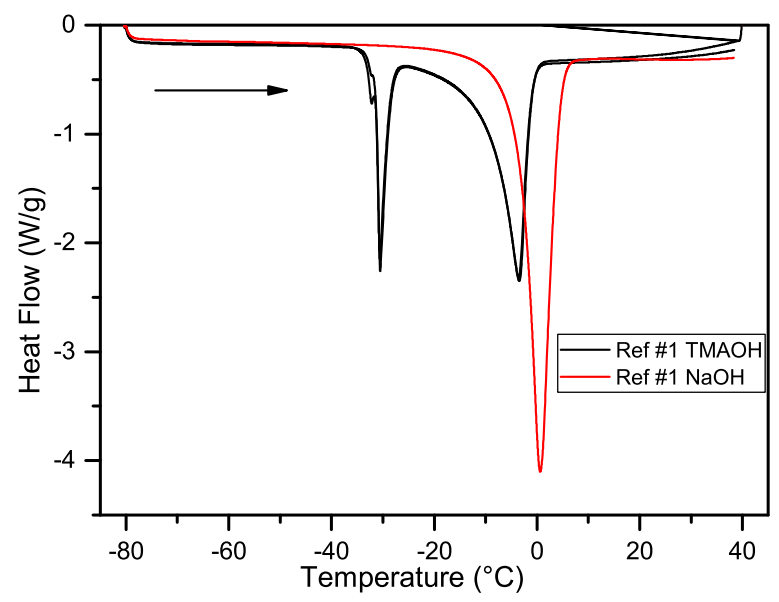

FIG. 7. DSC thermogram of the solid/liquid phase transitions for two reference solutions. Arrow indicates the direction of the cycle. Note the double melting peak for the solution loaded with TMA-OH. 


\section{CONCLUSIONS}

The freezing point $T_{c}$ of the liquid/solid phase transition of water depends on the ionic content. We have shown that $T_{c}$ is a colligative property of the ionic content of $\mathrm{ZrAc}$, probably one of the very few inorganic compounds able to mimic the ice-shaping effects of ISPs. Further, the amount of ice depends on the concentration of $\mathrm{Zr}$ in solution, independently on how the $\mathrm{pH}$ of the solutions is stabilized. The chaotrope hydrophilic TMA-OH is very strongly influenced by the freezing process. The expected ${ }^{23}$ clathrate organization of TMA-OH is destroyed by the presence of $\mathrm{ZrAc}$. We have estimated the sphere of interaction of the $\mathrm{Zr}$ cations on water molecules. The $\mathrm{Zr}$ cations display a radius of interaction of few $\mathrm{nm}$ that comprises hundreds of water molecules. These results give a hint on the kosmotropic and hydrophilic strength of $\mathrm{Zr}$ or tetrameric chains, which should populate the solutions. The topology of $\mathrm{Zr}$ structures is really complex and it strongly depends on the chemical conditions. In the three cases investigated here, the number of water molecules that do not nucleate is different. This reinforces the hypothesis that the length of $\mathrm{Zr}$ supramolecular organization is inversely proportional to the concentration. The final concentration of $\mathrm{Zr}$ in the remnant liquid water should, thus, not be the same. Nevertheless, we can not exclude further effects due to the $\mathrm{pH}$ of the studied solutions. We think that terahertz spectroscopy ${ }^{42}$ experiments and in situ microscopic measurements could be used to better understand the ice-structuring mechanism of ZrAc.

\section{ACKNOWLEDGMENTS}

We acknowledge Dr. C. Noirjean for her comments on the manuscript. The research leading to these results has received funding from the European Research Council under the European Community's Seventh Framework Programme (No. FP7/2007-2013) Grant Agreement No. 278004, FreeCo.

\footnotetext{
${ }^{1}$ See http://www1.lsbu.ac.uk/water/water_models.html for information about the several parameterizations of water molecules generally used in Molecular Dynamic and Monte Carlo simulations.

${ }^{2}$ P. V. Hobbs, Ice Physics, Oxford Classic Texts in the Physical Sciences (Oxford University Press, 2010).

${ }^{3}$ C. C. Pradzynski, R. M. Forck, T. Zeuch, P. Slavíček, and U. Buck, Science 337, 1529 (2012).

${ }^{4}$ A. Shibkov, Y. Golovin, M. Zheltov, A. Korolev, and A. Leonov, Physica A 319, 65 (2003)

${ }^{5}$ S. S. Peppin, J. A. W. Elliott, and M. Grae Worster, J. Fluid Mech. 554, 147 (2006).

${ }^{6}$ The Geophysics of Sea Ice, 1st ed., edited by N. Untersteiner (Springer, USA, 1986).
}

${ }^{7}$ T. Tojo, T. Atake, T. Mori, and H. Yamamura, J. Therm. Anal. Calorim. 57, 447 (1999).

${ }^{8}$ J.-L. Tosan, B. Durand, M. Roubin, F. Chassagneux, and F. Bertin, J. NonCryst. Solids 168, 23 (1994).

${ }^{9}$ A. C. Geiculescu and H. G. Spencer, J. Sol-Gel Sci. Technol. 16, 243 (1999).

${ }^{10}$ A. George and P. T. Seena, J. Therm. Anal. Calorim. 110, 1037 (2012).

${ }^{11}$ A.-C. Dippel, K. M. Ø. Jensen, C. Tyrsted, M. Bremholm, E. D. Bøjesen, D. Saha, S. Birgisson, M. Christensen, S. J. L. Billinge, and B. B. Iversen, Acta Crystallogr., Sect. A: Found. Adv. 72, 645 (2016).

${ }^{12}$ S. Deville, Adv. Eng. Mater. 10, 155 (2008).

${ }^{13}$ S. Deville, C. Viazzi, J. Leloup, A. Lasalle, C. Guizard, E. Maire, J. Adrien, and L. Gremillard, PLoS One 6, e26474 (2011).

${ }^{14}$ J. G. Duman and A. L. DeVries, Nature 247, 237 (1974).

${ }^{15}$ C. A. Knight and J. G. Duman, Cryobiology 23, 256 (1986).

${ }^{16}$ M. Griffith, M. Antikainen, W.-C. Hon, K. Pihakaski-Maunsbach, X.-M. Yu, J. U. Chun, and D. S. C. Yang, Physiol. Plant. 100, 327 (1997).

${ }^{17}$ O. Mizrahy, M. Bar-Dolev, S. Guy, and I. Braslavsky, PLoS One 8, e59540 (2013)

${ }^{18}$ M. Marcellini, C. Noirjean, D. Dedovets, J. Maria, and S. Deville, ACS Omega 1, 1019 (2016).

${ }^{19}$ The ice-shaping properties of $\mathrm{ZrAc}$ are independent of the supplier.

${ }^{20}$ S. Deville, C. Viazzi, and C. Guizard, Langmuir 28, 14892 (2012).

${ }^{21}$ Y. Koga, P. Westh, K. Nishikawa, and S. Subramanian, J. Phys. Chem. B 115, 2995 (2011).

${ }^{22}$ E. J. Nilsson, V. Alfredsson, D. T. Bowron, and K. J. Edler, Phys. Chem. Chem. Phys. 18, 11193 (2016).

${ }^{23}$ D. Mootz and R. Seidel, J. Inclusion Phenom. Mol. Recognit. Chem. 8, 139 (1990).

${ }^{24}$ Y. Zhang and P. S. Cremer, Curr. Opin. Chem. Biol. 10, 658 (2006).

${ }^{25}$ K. D. Collins and M. W. Washabaugh, Q. Rev. Biophys. 18, 323 (2009).

${ }^{26}$ A. A. Zavitsas, Curr. Opin. Colloid Interface Sci. 23, 72 (2016).

${ }^{27}$ P. Lo Nostro and B. W. Ninham, Chem. Rev. 112, 2286 (2012).

${ }^{28}$ R. M. Saeed, J. P. Schlegel, C. Castano, and R. Sawafta, Int. J. Eng. Res. Technol. 5, 405 (2016); available at http://www.ijert.org/view-pdf/ 14630/uncertainty-of-thermal-characterization-of-phase-change-materialby-differential-scanning-calorimetry-analysis.

${ }^{29}$ A. Clearfield, J. Mater. Res. 5, 161 (1990).

${ }^{30}$ C. Hagfeldt, V. Kessler, and I. Persson, Dalton Trans. 2004, 2142-2151 (2004).

${ }^{31}$ C. Hennig, S. Weiss, W. Kraus, J. Kretzschmar, and A. C. Scheinost, Inorg. Chem. 56, 2473 (2017).

${ }^{32}$ N. Rao, M. N. Holerca, M. L. Klein, and V. Pophristic, J. Phys. Chem. A 111, 11395 (2007).

${ }^{33}$ M. Bremholm, H. Birkedal, B. B. Iversen, and J. S. Pedersen, J. Phys. Chem. C 119, 12660 (2015).

${ }^{34}$ C. Tyrsted, N. Lock, K. M. Ø. Jensen, M. Christensen, E. D. Bøjesen, H. Emerich, G. Vaughan, S. J. L. Billinge, and B. B. Iversen, IUCrJ 1, 165 (2014).

${ }^{35}$ E. K. Leinala, P. L. Davies, and Z. Jia, Structure 10, 619 (2002).

${ }^{36}$ T. Sun, F.-H. Lin, R. L. Campbell, J. S. Allingham, and P. L. Davies, Science 343, 795 (2014).

${ }^{37}$ R. Drori, C. Li, C. Hu, P. Raiteri, A. L. Rohl, M. D. Ward, and B. Kahr, J. Am. Chem. Soc. 138, 13396 (2016).

${ }^{38}$ R. C. Dougherty and L. N. Howard, J. Chem. Phys. 109, 7379 (1998).

${ }^{39}$ S. Denys, A. M. Van Loey, and M. E. Hendrickx, Biotechnol. Prog. 16, 447 (2000).

${ }^{40}$ T. Asaoka, H. Kumano, M. Okada, and H. Kose, Int. J. Refrig. 33, 1533 (2010).

${ }^{41}$ Y. Koga, F. Sebe, and K. Nishikawa, J. Phys. Chem. B 117, 877 (2013).

${ }^{42}$ A. Shalit, S. Ahmed, J. Savolainen, and P. Hamm, Nat. Chem. 9, 273 (2017). 